\title{
Ocean-Colour Products for Climate-Change Studies: What are their ideal characteristics?
}

\author{
S. Sathyendranath ${ }^{\mathrm{a}, \mathrm{b}, *}$, Robert J.W. Brewin ${ }^{\mathrm{a}, \mathrm{b}}$, Thomas Jackson ${ }^{\mathrm{a}}$, Frédéric \\ Mélin $^{\mathrm{c}}$, Trevor Platt ${ }^{\mathrm{a}}$ \\ ${ }^{a}$ Plymouth Marine Laboratory, Prospect Place, Plymouth, PL1 3DH, UK \\ ${ }^{b}$ National Centre for Earth Observation, Plymouth Marine Laboratory, Prospect Place, \\ Plymouth, PL1 3DH, UK \\ ${ }^{c}$ Institute for Environment and Sustainability, Joint Research Centre, European \\ Commission, 21027 Ispra, Italy
}

\begin{abstract}
Ocean-colour radiometry is recognised as an Essential Climate Variable (ECV) according to the Global Climate Observing System (GCOS), because of its capability to observe various aspects of the marine ecosystem at synoptic to global scales. Yet the value of ocean colour for climate-change studies depends to a large extent not only on the decidedly important quality of the data per se, but also on the qualities of the algorithms used to convert the multi-spectral radiance values detected by the ocean-colour satellite into relevant ecological, bio-optical and biogeochemical variables or properties of the ocean. The algorithms selected from the pool of available algorithms have to be fit for purpose: detection of marine ecosystem responses to climate change. Marine ecosystems might respond in a variety of ways to changing climate, including perturbations to regional distributions in the quantity and
\end{abstract}

\footnotetext{
${ }^{*}$ Corresponding author. National Centre for Earth Observation, Plymouth Marine Laboratory, Prospect Place, Plymouth, PL1 3DH, UK

Email address: ssat@pml.ac.uk (S. Sathyendranath)
} 
in the type of phytoplankton present, their locations and in their seasonal dynamics. The ideal algorithms would be capable of distinguishing between these possibilities, and would not mistake one for the other. They would be robust to changes in climate, and would not rely on assumptions that might be valid only under current climatic conditions. Based on such considerations, we identify a series of ideal qualitative traits that algorithms for climate-change studies would possess. Necessarily, such traits would have to complement the quantitative requirements for precision, accuracy and stability in the data over long time scales. We examine the extent to which available algorithms meet the criteria, according to the round-robin comparisons of in-water algorithms carried out in the Ocean Colour Climate Change Initiative and where improvements are still needed.

Keywords:

\section{Introduction}

Ocean-colour radiometry from space is designed to measure spectral vari3 ations in remote-sensing reflectance in the visible domain of the electromag4 netic spectrum, following suitable corrections to the top-of-atmosphere signal 5 detected by satellites. It is recognised that variations in the absorption and 6 scattering of light by phytoplankton, and by associated material such as 7 detritus and yellow substance (coloured, dissolved organic matter), are the 8 principal causes of changes in ocean colour, at least for open-ocean waters. 9 The energy absorbed by phytoplankton may follow one of two possible pathways: it may be used for photosynthesis, the process by which light energy is used to convert inorganic material into organic matter; or it may be dis- 
sipated as heat (Sathyendranath \& Platt, 2007). The conversion of light energy into chemical energy through photosynthesis (also referred to as primary production) is the lesser of the paths, with thermal dissipation being the principal mode of energy dissipation.

Phytoplankton are present everywhere in the sunlit layers of the ocean in varying concentrations. Although microscopic in size and invisible (individually) to the naked eye, their presence exerts a controlling effect on the colour of the sea. Their collective photosynthesis at the global scale is enormous: it is currently estimated to be of the order of $50 \mathrm{GT}$ of carbon per year (Longhurst et al., 1995; Antoine et al., 1996; Friedrichs \& others, 2009), commensurate with net terrestrial primary production (Lurin et al., 1994). Phytoplankton are, therefore, an important mediator in the global cycle of carbon. They function at the base of the food chain in the ocean, and all larger organisms in the pelagic ecosystem rely on them, directly or indirectly, for their food. Because much of the light absorbed by phytoplankton is lost as heat, they also contribute to variations in the heat budget of the ocean Sath1991. Variations in phytoplankton modulate the depth distribution of solar heating in the ocean, and localised heating close to the surface of the ocean favours enhanced heat exchange with the atmosphere.

Feedback mechanisms are known to exist in the ocean: the vertical distribution of heating has a strong influence on the stability of the upper water column (Sathyendranath et al., 1991), and the interplay between stability and mixing determines the supply of nutrients to the surface mixed layer, as well as the average light available to phytoplankton in the layer for photosynthesis (Platt et al., 2003a,b). It is also recognised now that different 
types of phytoplankton affect marine biogeochemical cycles in different ways (Le Quéré et al., 2005; Nair et al., 2008; Sathyendranath, 2014). For example, large phytoplankton cells are likely to sink faster out of the surface layer, and are therefore more likely to transport organic carbon to the deep, than smaller cells. Some phytoplankton types produce calcium carbonate plates that surround their body, and some others use silica to form frustules that give them their characteristic shapes. Some phytoplankton are implicated in the production of dimethyl sulphate that can escape into the atmosphere, where it is known to act as a nucleus for cloud condensation. Thus, phytoplankton are key to life in the oceans; they are known to influence in a significant way two key aspects of all discussions on climate change: global carbon cycle and planetary heat budget; and we are still learning about other ways in which they influence our climate and our life.

For these reasons, phytoplankton lie at the heart of the Earth System, being at the interface between light and life in the oceans; it is this very interface that is probed by ocean-colour radiometry, which is therefore an indispensable tool in the study of climate change, and which has been recognised as an Essential Climate Variable in the Implementation Plan of the Global Climate Observing System (GCOS, 2004).

At the same time, it is not an easy tool to use: the radiometric signal is contaminated by atmospheric influence as the light travels from the sea surface to the satellite in outer space; small errors in instrument calibration or atmospheric correction can introduce significant errors in the inferred ocean signal. For example, Wang et al. (2013) have highlighted the importance of in-orbit radiometric calibrations for an ocean-colour instrument and their 
impact on remote-sensing reflectance and chlorophyll estimates when it is not done correctly and Wang et al. (2009) have shown that an improved atmospheric correction algorithm can improve retrievals of ocean-colour products. All satellites have a finite life span, and creating a long time series of qualitycontrolled data, fit for climate research, requires that the data from different ocean-colour sensors be stitched together in a seamless manner, to provide satellite-based direct observations of variability in the marine ecosystem over long time scales. This task is complicated because, to date, no two identical ocean-colour satellites have been launched into space. Each of the satellite ocean-colour sensors has represented an innovation, each with its own sensor specifications, calibration issues and specific algorithms designed to get the best results for that particular sensor. Thus, while recognising the primary role of ocean-colour data in climate-change studies, we also recognise the difficulties associated with the task of creating long, consistent, climate-quality ocean-colour data streams at the global scale.

A key step in creating ocean-colour products for climate research is the selection of appropriate algorithms for generating the products. Many algorithms are currently available for atmospheric correction of ocean-colour data, and for generation of biological, optical and biogeochemical products from the atmospherically-corrected data. Selection of the most suitable algorithms from possible candidate algorithms is not straightforward: each of them has its own advantages and limitations. In this paper, we discuss how a suite of algorithm-selection criteria can be developed, starting from the premise that the performance of the selected algorithms should be as robust as possible against potential modifications to the marine ecosystem in a 
changing climate. Furthermore, the selected algorithms should be those that best meet the requirements of the user community, for example, modellers who use ocean-colour data to provide initial conditions for models, and to validate model outputs.

The analysis presented here has focused on the end products, which are in-water properties. However, without appropriate atmospheric correction, the subsequent steps will fail, even with the best-performing of in-water algorithms. Hence, atmospheric correction algorithms merit equal attention, even though we recognise that they are not an end in themselves.

The concepts presented here were developed in the early days of the Ocean Colour Climate Change Initiative (OC-CCI) of the European Space Agency. Now, almost six years later, it is important to evaluate the extent to which the ocean-colour products generated by OC-CCI meet the ideals set out, and where the priorities lie for future work. Such an evaluation follows the presentation of the algorithm selection criteria.

\section{Potential Responses of the Marine Ecosystem to a Changing Climate and Implications for Algorithm Selection}

The marine ecosystem is known to respond to variations in atmospheric and oceanic forcing (winds, intermittent upwelling, seasonal change in stratification, warming, El Niño Southern Oscillation) in a variety of ways and on a variety of time and space scales (Di Lorenzo \& Ohman, 2013). Some of the ecosystem properties that are likely to be impacted by such changes in forcing at long time scales, including chlorophyll concentration (Martinez et al., 2009), marine primary production (Racault et al., 2016), phenology 
(Platt et al., 2003a; Racault et al., 2016), the area and boundary of ecological provinces (Devred et al., 2009) and phytoplankton community structure (Brewin et al., 2012), are accessible to remote sensing. These changes that are observed at interannual and decadal scales inform us that products that are designed for monitoring changes in the marine ecosystem at even longer scales corresponding to climate change, should be capabile of track these types of changes. The products mentioned above are derived from the spectrally-resolved water-leaving radiances estimated from the satellite signal after appropriate atmospheric corrections have been applied. The water-leaving radiances are controlled by the constituents of ocean water that absorb and scatter light in the visible domain (Figure 1), including phytoplankton, coloured dissolved organic matter and suspended sediments. The optical properties of the constituents are determined by the concentration of the material, and the type of material present. Before identifying suitable algorithms for climate studies, we have first to consider how the in-water constituents might be affected by climate change. In this, we may be guided by observed variability in marine ecosystem, in response to interannual variability in atmospheric forcing. We note that

- The total amount of phytoplankton in the surface waters, as indexed by chlorophyll-a concentration, might change (e.g., Martinez et al. (2009)).

- The phytoplankton community structure associated with the chlorophyll concentration might change, with consequent modifications in the size structure and pigment composition of the community (e.g., Brewin et al. (2012)), both of which can alter the optical characteristics of phytoplankton. 


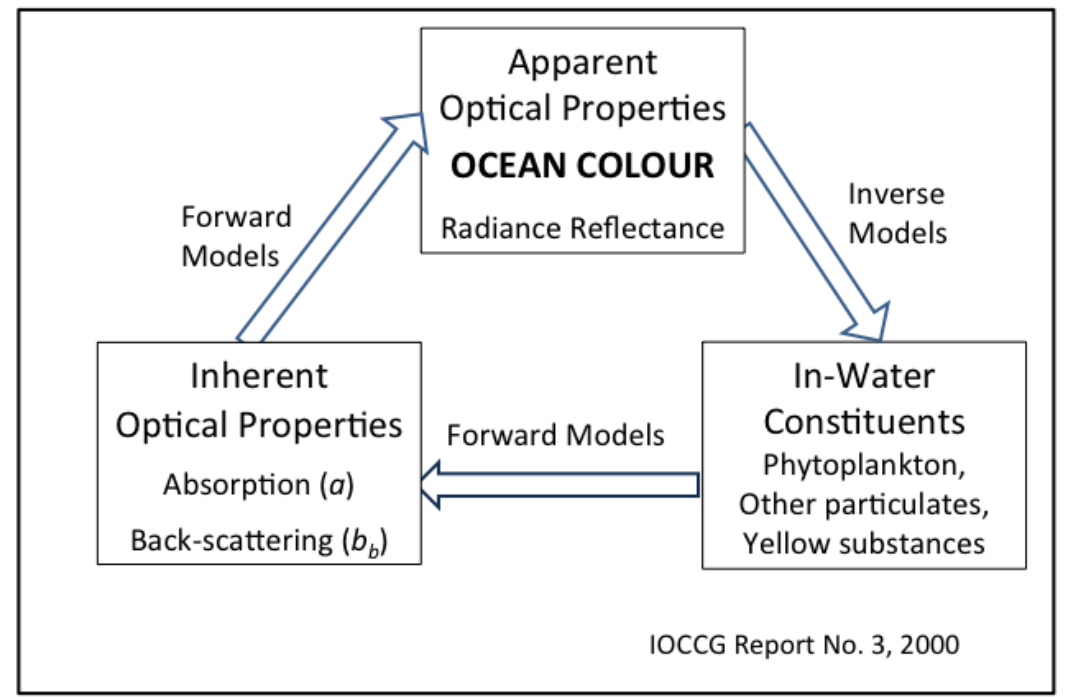

Figure 1: Schematic diagram illustrating the links between ocean colour, IOPs and inwater constituents that are exploited in remote sensing of ocean colour (adapted from ?). In ocean-colour remote sensing, the problem is to derive concentrations of in-water constituents and the corresponding IOPs, given ocean-colour data at the sea surface (related to spectrally-resolved water-leaving radiances). Note that the concentrations of in-water constituents are related to the water-leaving radiance via their IOPs, such as absorption and back-scattering coefficients.

- Other substances that absorb and scatter light in the visible domain might change, relative to chlorophyll-a. These might be, for example, the coloured organic dissolved material in the water or small organisms other than phytoplankton (e.g., bacteria) that are known to be strong contributors to back-scattering. Though such changes have not yet been reported directly, they are potential consequences of observed 
responses in the community structure noted above. It would therefore be prudent to prepare as well as we can, to monitor such potential changes.

- The geographical boundaries of ecological provinces in the ocean might change (e.g., Devred et al. (2009)).

- Finally, the phenology of phytoplankton dynamics (e.g., timing, amplitude and duration of phytoplankton blooms) might change (e.g., Platt et al. (2003a), Racault et al. (2016)).

Changes to community structure or to non-phytoplanktonic substances that absorb or scatter light can modify the light field underwater, with further consequences for the marine ecosystem and marine primary productivity. If our goal is to detect some, or all, of the kinds of changes listed above, then certain logical concequences follow, with respect to the types of algorithms that would be ideal for use in this context. Such logical implications for the choice of algorithms are listed below:

Implication 1: Algorithms should be robust in a changing environment. For example, if phytoplankton community structure changes, or if associated variables change, these alterations should not interfere with the performance of the algorithm for estimating chlorophyll-a. We note this condition as an implication, because there is an implicit assumption in many existing algorithms that many bio-optical variables in the ocean co-vary with each other, and notably with chlorophyll-a concentration. Such covariance is implicit in the assumption that open-ocean 
waters can be characterised as a single-variable system, with all biooptical properties covarying in one fashion or another, with chlorophyll (Morel ES Prieur, 197r7; Morel, 2009).

Implication 2: Retrievals of properties of the ecosystem should be independent of each other. In other words, emphasis should be on "direct" estimates of ecosystem properties, where we use the word "direct" to imply the use of a distinct optical signature that can be detected in remotesensing reflectance, to monitor an oceanic property. "Indirect" estimates based on correlations between elements of the ecosystem are not ideal in this context, since correlations between ecosystem constituents may not be stable in a changing climate. Note that this implication is intimately related to Implication 1 above: if we are not to confuse one type of change in the ecosystem with another type, then it is essential that there be no interdependencies in the algorithms used for the retrieval of those properties.

Implication 3: Use of empirical relationships in the algorithms should be minimal: they are of necessity based on observations in the past, and the past state of the ecosystem may not be a faithful guide to the future state. This implication arises in instances where the performance of an algorithm depends on current inter-relationships between various bio-optical components of the marine ecosystem. If the relationships change with climate, then the algorithm performance might be affected. Ideally, one would avoid using such algorithms for studies of climate change. 
Note that, in this paper, we have used the term "empirical" to refer to algorithms that relate water-leaving radiance or remote-sensing reflectance directly with a bio-optical property, based on observations of both quantities. On the other hand, the term "theoretical" is used to refer to those algorithms that relate radiance and reflectance to inherent optical properties, via an ocean-colour model (see Figure 1). The algorithms are referred to as "indirect" if they rely on empirical relationships with an intermediary product such as chlorophyll to make the link to satellite data.

These general considerations are examined in detail below, from various perspectives. We begin by analysing, from the perspective of climate-change studies, how algorithms have been traditionally partitioned into two types Case-1 and Case-2 - depending on the optical characteristics of the waters.

\section{Case 1 and Case-2 Waters}

Algorithms of the simplest type are designed for application in Case-1 waters, which are waters where phytoplankton and covarying substances are considered to be solely responsible for changes in ocean colour. Frequently, a different family of algorithms is invoked to deal with Case-2 waters, the optically-complex waters often encountered in coastal and inland water bodies where substances such as yellow substances (coloured dissolved organic matter) and suspended sediments vary independently of phytoplankton concentration. Ideally, algorithms designed for Case-1 and Case-2 waters would merge seamlessly at the boundary between the two water types. Most openocean waters belong to the Case-1 category, which covers, say, more than $90 \%$ of the global ocean. On the other hand, Case- 2 waters, which are 
mostly coastal in nature, are highly productive and therefore important to the livelihood of coastal communities. The user consultation undertaken by the OC-CCI project (Sathyendranath, 2011) revealed a clear priority for algorithms that would work across Case-1 and Case-2 waters (OC-CCI, 2011), or at least that would demarcate the boundary between the two. In selecting algorithms for climate studies, it would therefore be desirable to keep this eventual goal firmly in view. To understand what it would entail, let us take a brief look at the definitions of Case-1 and Case-2 waters. Morel \& Prieur (1977), who introduced this optical classification, intended it to be a qualitative classification of convenience. It is based on the relative contributions of substances in sea water that contribute significantly to variations in its optical properties. These constituents are phytoplankton, coloured dissolved organic matter (or yellow substances) and suspended sediments (Figure 2). Case-1 waters are those waters where the variability due to phytoplankton dominates the ocean-colour signal. Contributions from the other components may be taken either as negligible, or assumed to co-vary with the phytoplankton concentration. Chlorophyll concentration may be used as an index of phytoplankton biomass. This classification had the advantage of simplifying most oceanic waters from an optical perspective, into a single-variable system, in which all optical properties could be determined on the basis of chlorophyll concentration alone. On the other hand, Case-2 waters admit the independent, and often significant, contribution to IOPs from substances other than phytoplankton. Therefore, Case-2 waters are multi-variable optical systems. If we arrange the set of all possible cases of optical variability in a three-component system (Figure 2), then Case-1 waters emerge as a subset 


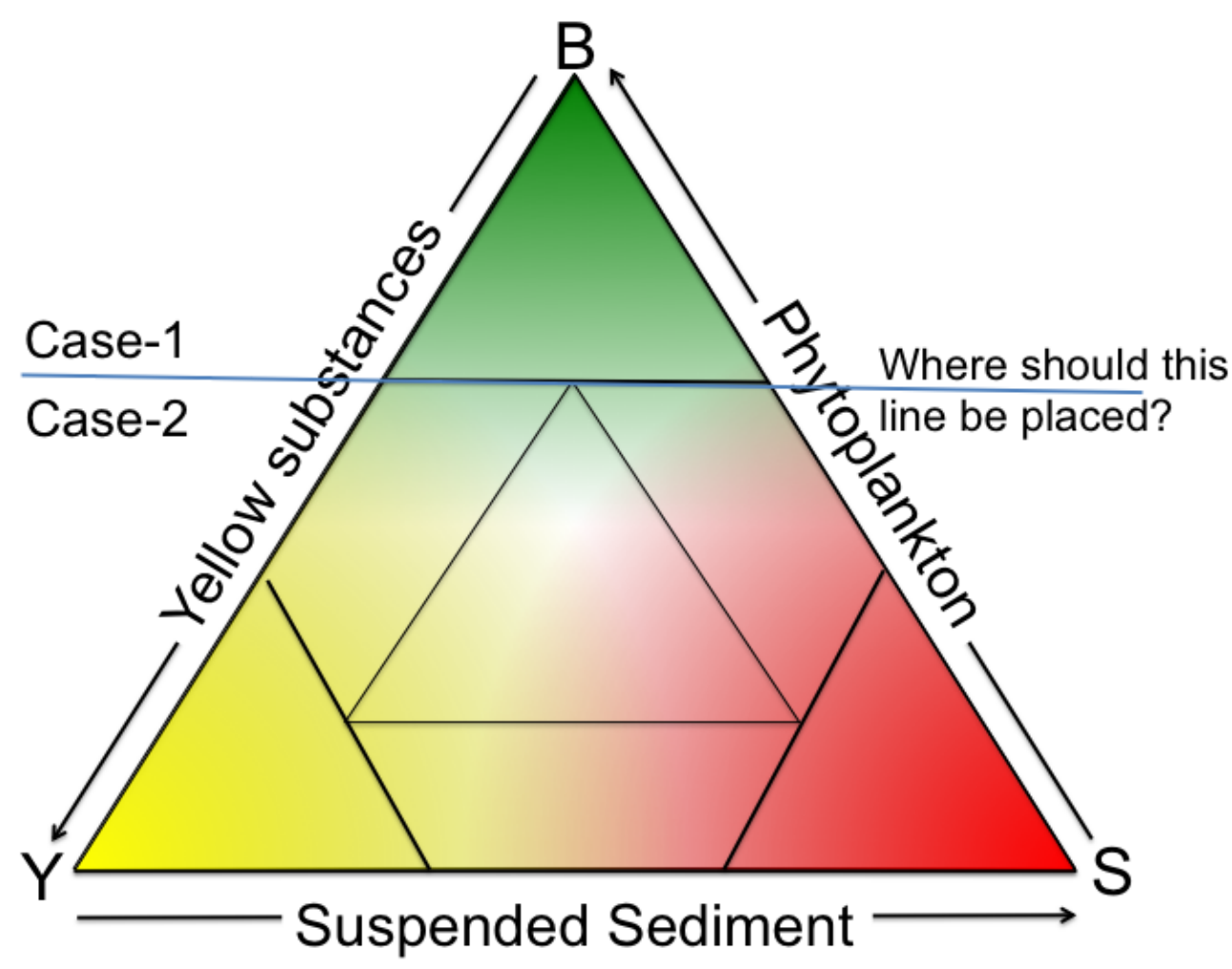

Figure 2: Tripartite diagram (from Prieur \& Sathyendranath (1981) and Sathyendranath (2000)), showing Case-1 and Case-2 waters according to the relative contributions of phytoplankton, dissolved organic matter (yellow substances) and suspended sediments to variations in a selected optical property. of Case-2 waters (Sathyendranath \& Morel, 1983). The classification may be illustrated as follows, using equation 1 for the absorption coefficient:

$$
a(\lambda)=a_{w}(\lambda)+B a^{B}(\lambda)+a_{y}(\lambda)+a_{d}(\lambda) \ldots
$$

where $a(\lambda)$ is the total absorption coefficient $\left[\mathrm{m}^{-1}\right]$ at wavelength $\lambda[\mathrm{nm}]$, $a_{w}(\lambda)$ is the absorption coefficient by pure water, and $B a^{B}(\lambda)$ is the absorp- 
tion coefficient of phytoplankton, expressed as the product of chlorophyll concentration $\left(B,\left[\right.\right.$ Chl-a $\left.\left.\mathrm{L}^{-3}\right]\right)$ (treated here as an index of phytoplankton biomass), and a chlorophyll-specific absorption coefficient for phytoplankton, $a^{B}(\lambda)\left[\mathrm{Chl}-\mathrm{a}^{-1} \mathrm{~m}^{2}\right]$. In addition, there are other contributions to absorption, for example from yellow substances, $a_{y}(\lambda)$ and detritus $a_{d}(\lambda)$. In Case-1 waters, $a(\lambda)$ is modelled as a function of chlorophyll concentration with the additional terms such as $a_{y}$ and $a_{d}$ being treated as functions of chlorophyll-a. In Case-2 waters, the additional terms have to be taken into account as variables independent of chlorophyll-a. Because the classification is an optical one, the relative importance of various components to the IOPs is wavelength-dependent. The classification does not lend itself readily to a quantitative approach, and any partition between the two classes would be arbitrary. For example, in the tripartite diagram of Figure 2, it would be a matter of choice where one might place the line of demarcation between Case- 1 and Case-2 waters. The figure also shows that some substances other than phytoplankton are always present even in natural Case- 1 waters. Any deviation from the Case-1 assumption would introduce errors into Case-1 type of algorithms. But some of them may be less vulnerable to this type of errors than others.

The classification of waters into Case-1 and Case-2 has served the oceancolour community well, but the fundamental differences between typical Case-1 algorithms (empirical, single-variable) and Case-2 algorithms (modelbased, multi-variate) do not facilitate the blending of algorithms in a seamless fashion at the boundary (necessarily arbitrary) between the two classes. At the same time, and as we shall see in the next section, there is increasing 
evidence that the Case-1 algorithm maay not be as robust as previously believed, even in opan-ocean waters (Bouman et al., 2000; Siegel et al., 2005; Morel et al., 2006). If we persevere with separate classes of algorithms in Case-1 and Case-2 waters for climate-change studies, we should at least try to define the domains of applicability of the separate algorithms. Even this would not be straightforward: although methods have been proposed (e.g., Lee \& Hu (2006)) to discriminate between Case-1 and Case-2 waters, it is doubtful whether they would be equally effective in waters dominated by yellow substances, detritus or sediments.

From the perspective of climate-change studies, this situation is not satisfactory, and a long-term vision should embrace the goal of having Case-1 and Case-2 algorithms that are technically and conceptually similar, such that they could be blended across boundaries without introducing artefacts. It would provide seamless, global coverage of products across all coastal and marine waters, and potential extension to inland water bodies (which are also often extreme examples of Case-2 waters). Since Case-2 algorithms could be applied, in principle, to the optically-simpler cases, we anticipate that algorithms successful across both Case-1 and Case-2 waters will emerge from the Case-2 family of algorithms rather than the other way round. Sathyendranath et al. (1989) have shown that a single algorithm that would work across all combinations and concentrations of contributing substances might not be possible, and that branching algorithms might be necessary, to deal with subsets of possible cases.

The consequences for algorithm selection are:

Implication 4: Selected Case-1 algorithms should be accompanied by some 
estimates of the increased uncertainties in products when they are applied to Case-2 waters.

Implication 5: Case-1 algorithms should aim to incorporate some of the capabilities of Case-2 algorithms to discriminate between contributions from different constituents to ocean colour, albeit for conditions that might reasonably be expected in open-ocean waters. In other words, Case-1 algorithms should evolve from single-variable approaches to multivariable approaches, making them similar in structure to Case-2 algorithms, but optimised for open-ocean conditions. This would, in principle, have the added benefit of improving the accuracy of chlorophyll retrievals.

Implication 6: Branching algorithms may be considered, for seamless blending of Case-1 and Case-2 waters, as long as no single algorithm is available that is found to work uniformly well across both Case-1 and Case-2 waters.

Let us next turn our attention to Case-1 algorithms, which are the bestknown of all available alogirthms.

\section{The OC4 Algorithm of NASA: Example of a Successful and Well-tested Algorithm for Case-1 Waters}

Ocean-colour remote sensing has a history of more than three decades, and many successful algorithms have been established over the years. In the context of this paper, the relevant algorithms are those that have global application, have been validated extensively and have been implemented in 
a processing chain for routine operation. Such algorithms were compared and evaluated recently (Brewin et al., 2015a). They include a number of empirical algorithms - the NASA OC4 algorithm (O'Reilly et al., 2000), the NASA OC2S (O'Reilly et al., 2000), the MERIS algorithm proposed by Morel \& Antoine (2011), the OCI algorithm of Hu et al. (2012) and some others with more of a theoretical basis (Garver \& Siegel, 1997; Lee et al., 2002; Maritorena et al., 2002; Franz \& Werdell, 2010; Devred et al., 2011). Brief descriptions of each of these algorithms is availble in Brewin et al. (2015a). An excellent starting point for the discussion of algorithm selection for climate studies would be the well-known and most widely-accepted of these algorithms: the OC-4 series of algorithms (Figure 3) developed and adopted by NASA for estimating chlorophyll-a concentration. These algorithms use band ratios of water-leaving radiances at three wavebands in the visible (e.g., 443, 490 and $510 \mathrm{~nm}$ relative to $555 \mathrm{~nm}$ in the case of the NASA SeaWiFS sensor). In an implementation for a given pixel, any one of these ratios could be a potential predictor of chlorophyll concentration. But of the three ratios, only the one with the greatest magnitude is used in an empirical polynomial relationship. The choice of the band ratio with the highest magnitude has the advantage of avoiding, in particular cases, the use of bands with low-amplitude signals and potentially high retrieval errors. The algorithms are based on a large number of data points; they have been tested and validated extensively (Brewin et al., 2015a); and are widely used. They have a broad user base. The software packages developed by NASA for implementing the algorithms on CZCS, OCTS, SeaWiFS, MERIS, MODIS and other sensors are freely available to the user community, as is the source code. A tradition of outstanding user 
support has been established at NASA to deal with enquiries and comments from the user community. For all these reasons, this suite of algorithms may be considered to be the current industry standard. Similar algorithms are in use, for example, in the MERIS Case-1 processing software.
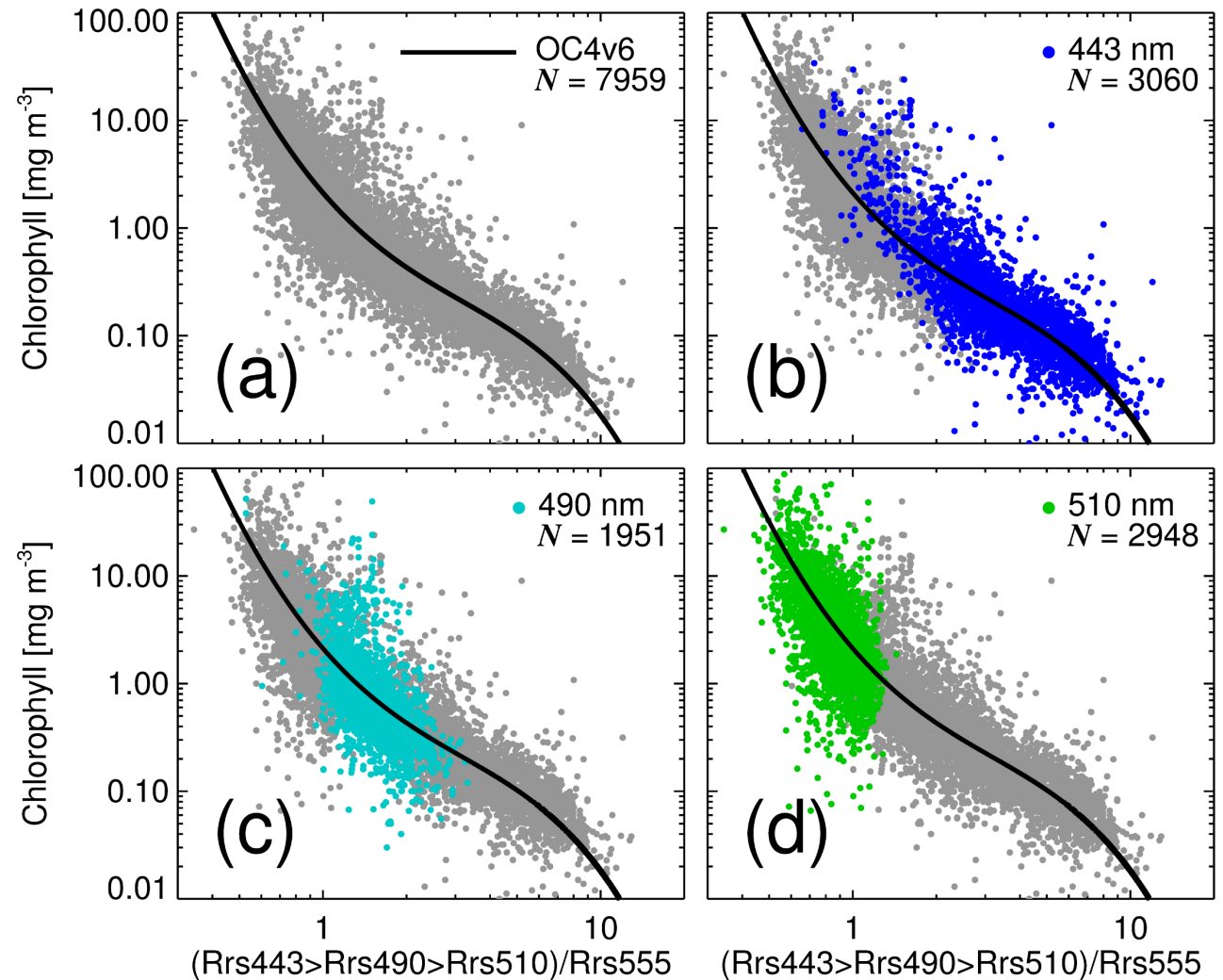

Figure 3: The NASA OC-4v6 algorithm, which is based on the ratios of water-leaving radiances at 443, 490 and $510 \mathrm{~nm}$, each normalised to that at $555 \mathrm{~nm}$. The maximum of the three ratios (highlighted in green, cyan and blue) is used in the empirical algorithm. The fitted curve is a polynomial, along the lines presented by O'Reilly et al. (1998). The number of observations $N=7959$ in this figure. Data from OC-CCI Version 2 match-up database Valente et al. (2016). 


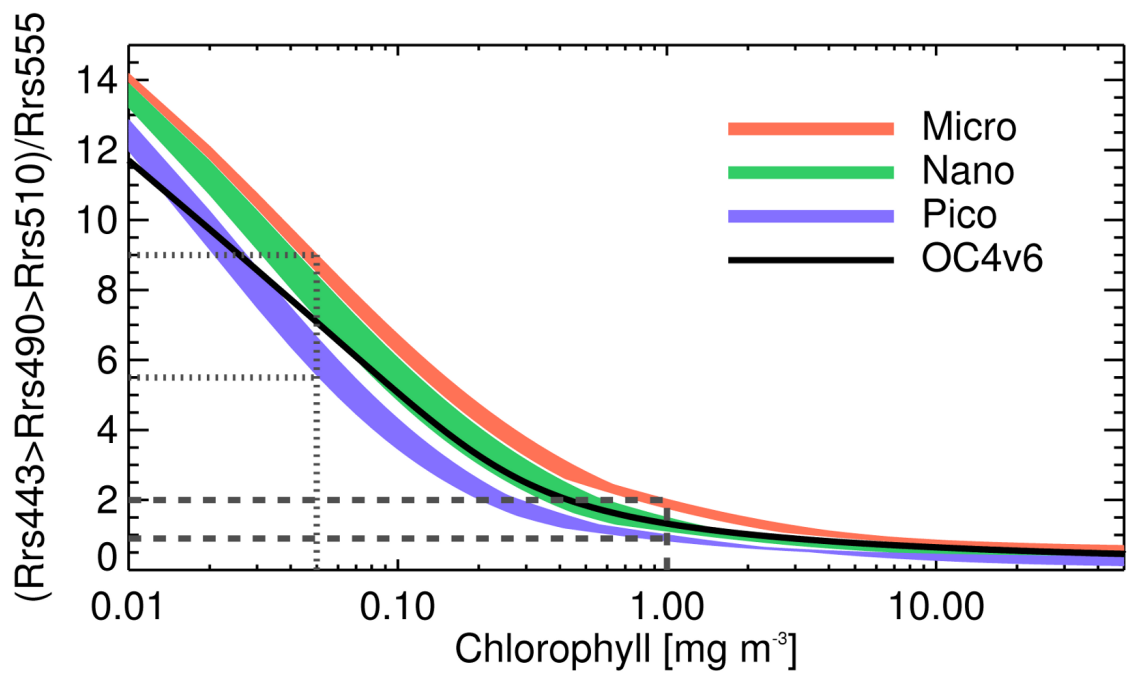

Figure 4: Remote-sensing reflectance modelled according to Gordon et al. (1988) as a function of chlorophyll concentration, using specific phytoplankton absorption spectra for different size classes proposed by various authors (Brewin, 2011; Devred et al., 2011; Ciotti \& Bricaud, 2006). The shaded areas show the region covered by all the models. Here, absorption by detritus and dissolved organic matter are computed according to Bricaud et al. (2010); Morel (2009); absorption by pure water according to Pope \& Fry (1997); particle back-scattering according to Huot et al. (2008); and back-scattering by pure water according to Zhang \& Hu (2009); Zhang et al. (2009). See also Sathyendranath (2014). The NASA OC4v6 algorithm is shown in black. Note how the algorithm is close to the picoplankton model for low chlorophyll values, to the nanoplankton at intermediate concentrations, and to the microplankton model at high concentrations, following the structure of the current marine ecosystem. The dashed lines show a couple of examples of changes in the remote-sensing reflectance ratio, when chlorophyll concentration is held constant, and the phytoplankton community is allowed to change from all picoplankton to all microplankton.

But, notwithstanding the admirable qualities of the OC-4 algorithms, they also have some less-than-ideal properties in the context of climate- 
change studies. Based on the discussions in Section 2, one such property is the empirical nature of these algorithms. The inferred relationship between chlorophyll and reflectance ratios depends implicitly on the change in phytoplankton community structure with change in chlorophyll concentration as seen in Figure 4 (see also (Sathyendranath, 2014)), and on the covariance of other absorbing and scattering material with chlorophyll-a. These relationships may change geographically (Loisel et al., 2010; Szeto et al., 2011) and with time (Dierssen, 2010). Typically, in today's ocean, there is a general tendency for the phytoplankton community to change from small-cell-dominated populations in oligotrophic waters to large-cell-dominated ones in eutrophic waters (Chisholm, 1992; Uitz et al., 2006; Brewin et al., 2010, 2015b). Moreover, the optical properties of phytoplankton change with size. The effects of such changes on reflectance ratios are incorporated implicitly in global band-ratio algorithms, as illustrated in Figure 4 and has also been demonstrated by Dierssen (2010). Because of the shifts in the band ratios used in the OC-4 algorithm, it is often difficult to say, from the chlorophyll concentration alone, which band ratio was used in the computation (see Figure 3). It would not therefore be possible for a modeller to work backwards from the chlorophyll concentration to estimate the band-ratio that yielded the given concentration, unless the band-ratios themselves were available. Multi-year in situ data are used to generate the algorithms, and under climate change, we have to accept that the past may not be a reliable guide to the future. Furthermore, in the context of climate change, the inter-annual variability is important, and we may ask: Is there significant inter-annual variability in the performance of the algorithm? Is it likely to become significant in the 

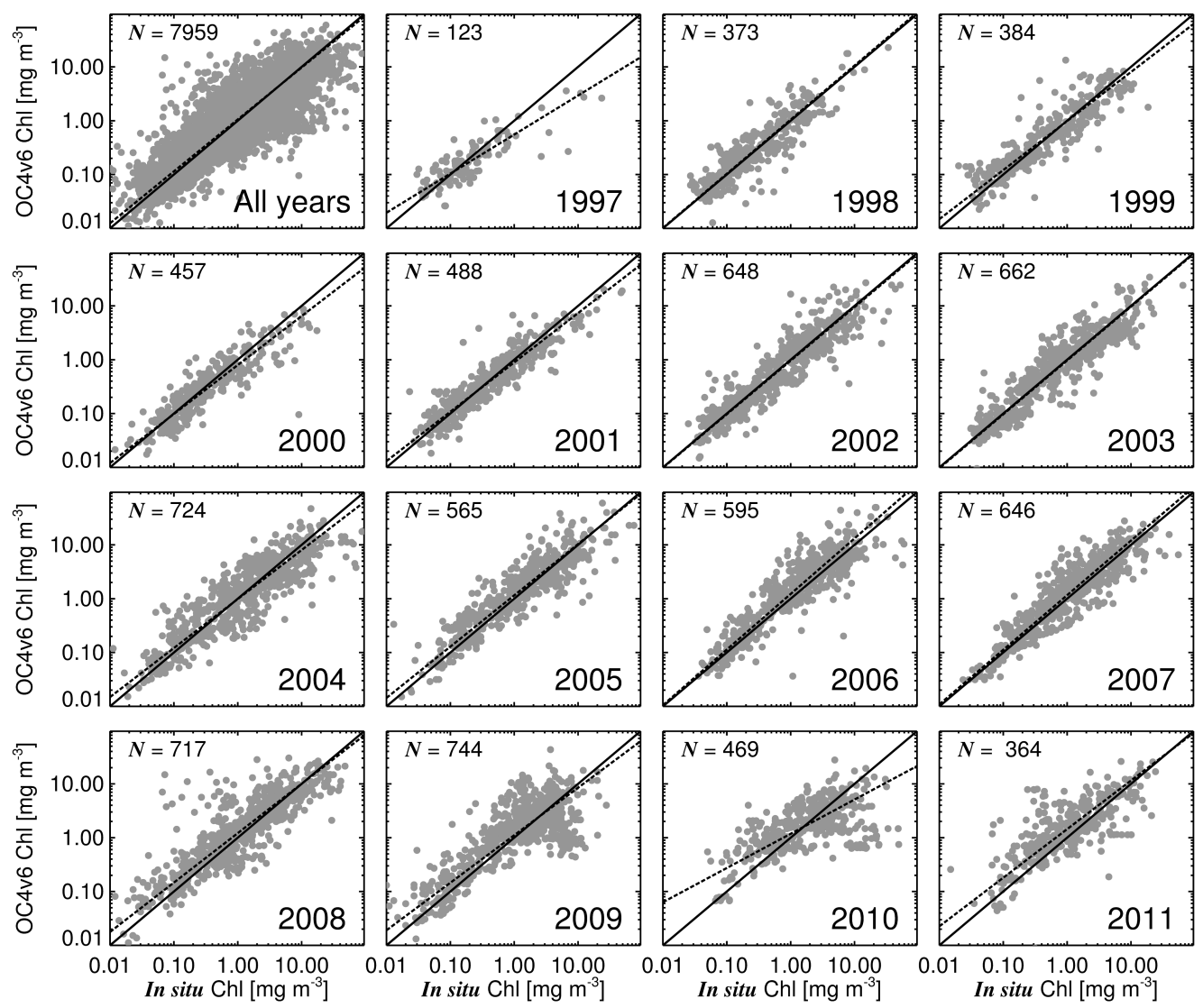

Figure 5: Updated from (Brewin, 2011) showing data partitioned according to year of data collection, from 1993 to 2011, based on OC-CCI Version 2 in situ match-up database (Valente et al., 2016). The original chlorophyll data, and chlorophyll-a computed using OC4v6 algorithm are shown in each panel, along with the one-to-one line (continuous) and the best fit to the data (dashed line). The top left panel shows the results for all the years combined. Note that, the fit is very close to the one-to-one line for all the years, with the exception of 1997 and 2010. For 1997m the change in slope appears to be imposed by a small number of outliers, and the 2010 data appear to be relatively noisy. 
To address the first question, a year-by-year analysis has been carried out on the OC-4 algorithm (Figure 5). The figure shows no evidence of significant inter-annual variation in performance of the algorithm, for those years for which large numbers of observations are available, which provides some reassurance about its suitability as an algorithm for use in climate-change studies, at least for the period studied. But, there is some emerging evidence that phytoplankton community structure is susceptible to climate variability, see for example, the report of Li et al. (2009) about the recent change in phytoplankton community in the Arctic. The evidence in Figure 5 may therefore be incomplete (because not all regions are equally well represented in the validation data). Under the circumstances, precautionary principles dictate that one has to vigilant, and not assume that past performance would guarantee future performance. To continue the validation exercise, one would require a large number of data points for yearly validation of the algorithm as done in Figure 5. Since climate impacts are not expected to be uniform across all locations, global coverage would be required for the validation data. Furthermore, the OC-4 algorithm is an empirical algorithm designed to relate water-leaving radiances directly to chlorophyll concentration, and one would have to resort to other algorithms to retrieve the inherent optical properties (IOPs) that are also ocean-colour products of interest in climate-change studies, which would make it difficult to ensure consistency across algorithms. All these arguments point to the wisdom of developing, in parallel, other algorithms that would provide a theoretical basis for OC-4 and other empirical algorithms.

The implications for algorithm selection that can be drawn from this part 
of the analysis are the following:

Implication 7: If empirical algorithms were selected as candidate algorithms for climate-change studies, then it would be essential to provide a theoretical underpinning to the algorithms, so as to enhance their robustness to climate change or to establish the extent of their potential sensitivity to possible climate-change-related modifications to the marine ecosystem.

Implication 8: If novel, model-based algorithms, lacking the long and successful history of OC4-type of algorithms, emerged as successful candidates for generation of ocean-colour products for climate studies, it would be desirable to reconcile the two types of algorithms through theoretical analyses. It would also be extremely valuable to continue to have access to OC4-type of algorithms as a baseline for comparison. Any divergence between the two algorithms, at a particular time or at given locations, would signal where additional work was needed as a priority.

\section{Detection of Phytoplankton Types}

Ocean-colour science is in a state of dynamic growth: in addition to standard products such as chlorophyll concentration and IOPs, novel products are still emerging. These new applications include detection of phytoplankton functional types and size structure from ocean-colour data (Nair et al., 2008; Sathyendranath, 2014). Since both these properties of the marine ecosystem might be vulnerable to climate change, let us consider how the corresponding products are generated and what might be the implications for algorithm selection. 

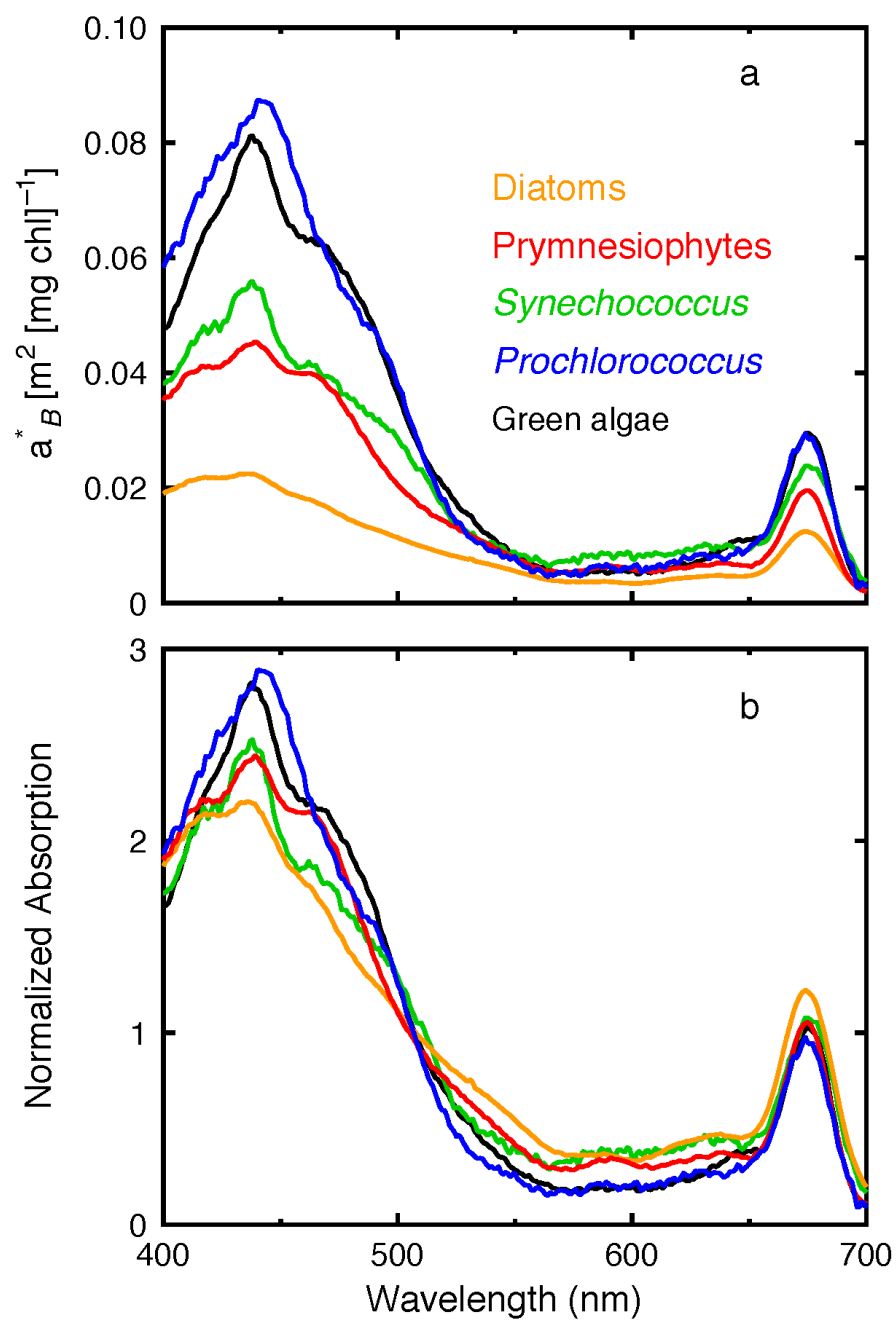

Figure 6: Examples of absorption spectra of phytoplankton samples from the field, with the dominant type (according to pigment analysis) identified. (a) Specific absorption spectra per unit chlorophyll concentration, highlighting the differences in the magnitude of the spectra with type. (b) Absorption spectra normalised such that the integral of each of the curves (from $400-700 \mathrm{~nm}$ ) is one, highlighting the differences in the shape of the spectra. From (Sathyendranath \& Platt, 2007). 
Absorption characteristics of phytoplankton of different types often have features that are distinct from each other (see Figure 6). Frequently, size and function are interconnected. For example, diatoms tend to be large cells that participate actively in the silica cycle in the ocean, and large cells tend to sink faster than small cells, and contribute more to the export of carbon from the surface ocean. The distinct optical features of phytoplankton types may include differences in the magnitude of the absorption coefficient per unit chlorophyll concentration, or variations in the spectral characteristics, as shown in Figure 6. From a remote-sensing perspective, it is the changes in spectral shape, and not the magnitude, that provide remotely-detectable signals for discrimination of different types of phytoplankton. This is because a change in magnitude of the signal at a single wavelength could arise from change in chlorophyll concentration or from a change in community, or from a change in any other bio-optical substance. Hence the reliance on spectral shape, to distinguish one type of substance from another. Methods exist, and are being developed, to exploit these distinguishing spectral features for detection of certain functional types from spectrally-resolved ocean-colour data (Nair et al., 2008; Sathyendranath, 2014).

Identification of phytoplankton community structure requires that the total phytoplankton absorption (Equation 1) be expressed as the sum of absorptions due to the different types of phytoplankton in the community, the absorption coefficient of each component being expressed as the product of its chlorophyll concentration and the corresponding absorption coefficient per unit chlorophyll concentration: 


$$
B a^{B}(\lambda)=\Sigma_{i=1}^{N} B_{i} a_{i}^{B}(\lambda),
$$

where $N$ is the number of phytoplankton types being considered, $B_{i}$ is the chlorophyll concentration of the $i^{\text {th }}$ component, and $a_{i}^{B}(\lambda)$ is the specific absorption coefficient of the same component. Although Figure 6 and Equation 2 refer to changes in absorption characteristics, discrimination based on spectral characteristics of back-scattering has also been proposed (Kostadinov et al., 2009, 2010). Clearly, the methods would be limited by the number of wavebands available for spectral discrimination between functional types (hyper spectral sensors would have an advantage here). Furthermore, they would not be applicable in the absence of any discriminating spectral signatures. Such features, when available, are small signals (Figure 6), and therefore high precision in signal is essential for application of the methods. Sometimes, it may be possible to detect only the dominant type, without resolving the minor components (for example, see methods of Sathyendranath et al. (2004) and (Alvain et al., 2005). A further problem is plasticity in the optical properties of phytoplankton types in response to growth conditions (Nair et al., 2008). Notwithstanding these limitations, the availability of hyper-spectral remote-sensing data is making it possible to introduce novel methods for detecting phytoplankton types from space (Bracher et al., 2009).

Because of these difficulties with approaches designed to detect phytoplankton types directly from their optical signatures, indirect methods have also been proposed that link community structure or size structure with chlorophyll concentration. Such methods (Figure 4), rely on the general observation that there is a relationship between community structure and 
chlorophyll concentration (or other indices of phytoplankton abundance). Under climate-change however, there is always the possibility that such relationships might be perturbed. The preference, therefore, in the present context, is for development and use of methods that rely on the optical signatures of the target phytoplankton type, rather than on correlations established from historical data. We recognise, nevertheless, that comparison of empirical and theoretical methods, and their reconciliation, could also play a useful role in climate research: systematic differences that emerge between different types of algorithms could be the first hint of a change in the ecosystem structure.

For algorithm selection then, we should consider:

Implication 9: Spectrally-resolved water-leaving radiances, in combination with bio-optical algorithms that allow retrieval of spectral variations in phytoplankton optical properties, are key to detection of phytoplankton types from ocean-colour data, especially in a climate-change context. Availability of information on phytoplankton types would facilitate resolution of the ambiguity in interpretation of algorithms based on bluegreen ratios.

Implication 10: If the chlorophyll concentration estimated as sum of contributions from each phytoplankton type could not be reconciled with that estimated from blue-green ratios, then it would be an indication that further research should be undertaken. 


\section{Construction of time series and phytoplankton phenology}

The most notable feature of chlorophyll time series developed from remote sensing of ocean colour is the seasonal signal. The seasonality is of extreme importance to ecosystem function because the life cycles of many organisms, invertebrate and vertebrate, are strongly coupled to it. More strictly, they are tied to its phase, a property that is variable between regions and between years, because it is controlled by physical forcing, local or remote, which is neither uniform nor constant. For the same reasons, the phase of the seasonal cycle is sensitive to climate change. Seasonality in lifecycle processes, together with its variations both inter-annual and secular, is often referred to as phenology. In the ocean, phenology of phytoplankton is of fundamental significance to carbon fluxes relevant to mitigation of the greenhouse effect. That it can have profound impact at higher trophic levels has been demonstrated with great clarity (Platt et al., 2003a; Koeller et al., 2009). In other words, the trophic economy of the entire ocean ecosystem, and the important fluxes of carbon associated with it, are vulnerable to perturbations of phytoplankton phenology, which can be observed from remote sensing of ocean colour. Phenology extracted from ocean-colour data constitutes a key resource to test whether models are able to produce seasonal dynamics realistically. In analyses of time-series data, the seasonal signal has to be resolved and isolated before any residual long-term signal related to multi-year variability or climate change can be revealed. Interruptions in data stream lead to uncertainties in phenology: the frequency of observations should be sufficient to resolve seasonality in the signal. We should therefore consider: 
Implication 11: The selected algorithm(s) should perform routinely, and globally, and should minimise gaps in data.

\section{Suitability of Products in Modelling Studies}

A major application of ocean-colour products in the climate context is anticipated to be in modelling studies. Many products of ocean-colour are inter-related to each other and various products may be used in different parts of a model. Computation of primary production in the ocean may be used to illustrate the point. Primary production $P\left(\mathrm{mg} \mathrm{Cm}^{-3} \mathrm{~h}^{-1}\right)$ at a given time $(t)$ and depth $(z)$ in the water column may be expressed, in models of photosynthesis, as the product of chlorophyll concentration $B$, the parameter $P_{m}^{B}\left(\operatorname{mgC}\left(\mathrm{mg} \mathrm{Chl}^{-1} \mathrm{~h}^{-1}\right)\right.$ that describes photosynthetic rate at saturating light levels, the initial slope $\alpha^{B}\left(\mathrm{mgC}\left(\mathrm{mg} \mathrm{Chl}^{-1} \mathrm{~h}^{-1}\left(\mathrm{~W} \mathrm{~m}^{-2}\right)^{-1}\right)\right.$ of the photosynthesis-irradiance curve, and a function $(f)$ of available light $E\left(\mathrm{~W} \mathrm{~m}^{-2}\right)$ as in Equation 3 below:

$$
P(z, t)=B(z) P_{m}^{B}(z, t) f\left(\int E(z, t, \lambda) \alpha^{B}(\lambda) \mathrm{d} \lambda / \mathrm{P}_{\mathrm{m}}^{\mathrm{B}}\right) .
$$

Note that the available light $E$ and the parameter $\alpha^{B}$ are both functions of wavelength $(\lambda)$. Chlorophyll concentration $B$ at the surface is accessible to remote sensing; to determine its value, we exploit (implicitly or explicitly), a function $(h)$ of absorption coefficient $a$ and the back-scattering coefficient $b_{b}$ (Equation 4):

$$
B(z=0)=h\left(a(\lambda), b_{b}(\lambda)\right) .
$$

The light available at depth $(z)$ in the ocean is determined by the light available at the sea surface, and the diffuse attenuation coefficient $(K)$, which 
determines the rate of decrease of irradiance with depth, and is another function $(g)$ of absorption and backscattering coefficients:

$$
E(z, \lambda)=E(0, \lambda) \exp -\left(\int_{0}^{z} K\left(z^{\prime}, \lambda\right) \mathrm{d} z^{\prime}\right)
$$

and

$$
K(z, \lambda)=g\left(a(z, \lambda), b_{b}(z, \lambda)\right) .
$$

The initial slope $\alpha^{B}$ is related to the specific absorption coefficient of phytoplankton $a^{B}$, and the maximum quantum yield of photosynthesis $\phi_{m}$ (Platt \& Jassby, 1976):

$$
\alpha^{B}(\lambda)=a^{B}(\lambda) \phi_{m}(\lambda)
$$

The example shows how ocean-colour products such as chlorophyll concentration $(B)$, the IOPs (such as the total absorption coefficient $a$, the specific absorption coefficient of phytoplankton $a^{B}$ and back-scattering coefficient $b_{b}$ ) and the diffuse attenuation coefficient $K$ are all interconnected. They are also related to certain model parameters, and they appear in different parts of the computation of primary production. The interconnectedness of products has implications for algorithm selection:

Implication 12: Different ocean-colour products for climate-change studies have to be consistent with each other. One way to test consistency would be to examine whether the products taken together can close the radiation budget with minimal error. This is an essential requirement, but not sufficient, since in a budget, error in one component may be compensated by an opposite error in another component. 
Implication 13: IOPs have to be fully wavelength-resolved for use in applications such as computation of primary production, since photosynthesis depends on the weighted integral of products like $E(\lambda) \alpha(\lambda)$ taken over the visible domain. This implies a preference for retrieval algorithms that function well at all available wavelengths, rather than at only selected wavelengths.

\section{Consistent Products from Different Sensors}

One of the requirements for generating long time series of ECVs from ocean-colour data is that the products be consistent across different sensors. All the ocean-colour sensors currently available have at least some wavebands not used by others, with the consequence that the water-leaving radiances and IOPs retrieved for the different sensors are not all calculated for the same wavebands. This matter has to be addressed before spectral optical properties from various sensors available at a particular time can be merged. Further, it would have to be dealt with before time series of optical properties could be generated without shifts in wavelengths when availability of sensors (inevitably) changed. Any intersensor bias might lead to spurious trends in time series data (Mélin, 2016), and to misleading conclusions in climate-change studies. These considerations lead to the following choices for generation of merged products:

Implication 14: For consistency across products from different sensors, the in-water retrievals should be based on a common reflectance model. When band-shifting is necessary, the same reflectance model should also be used for interpolation between wavebands. 
Implication 15: Inter-sensor bias has to be corrected, before data from multiple sensors are merged.

\section{Uncertainties in ocean-colour products}

All the above considerations notwithstanding, the algorithms of choice should satisfy the user requirements with regard to uncertainties, and so the uncertainties associated with each product should be specified. The choice of metrics for reporting uncertainties should be commonly-used in the community to facilitate comparisons. It has been typical in the ocean-colour field to provide global estimates of uncertainties, but for many applications, such as the use of the products in data assimilation, it is useful to have uncertainties specified on a per-pixel basis. The requirement to provide pixelby-pixel error estimates is a challenge that could be addressed using optical classification of pixels in conjunction with class memberships in every pixel (Moore et al., 2009). Once uncertainties are established for each class, those associated with any pixel can be evaluated on the basis of the membership of the different classes within the pixel at that time.

Uncertainties may be based on rigorous error propagation studies, in which case uncertainties at each step of the algorithm (if known) can be used to establish the total error propagated to the final product. Another option is to base uncertainties on comparison with in situ observations, treated as the truth. In the user consultation undertaken in the OC-CCI project, modellers expressed a clear preference for uncertainties established on the basis of validation (comparison with corresponding in situ data).

Implications for algorithm selection are: 
Implication 16: Selected algorithms should yield each of the products with minimal uncertainties.

Implication 17: The metrics selected for uncertainty characterisation should meet user requirements.

Implication 18: The metrics should be implemented on a per-pixel basis.

Implication 19: Since many algorithms use multiple wavebands, it is not only the uncertainties at individual wavebands that are important, but also the shape of the retrieved optical properties, whether they be the remotesensing reflectance after atmospheric correction, or the inherent and apparent optical properties derived from them.

\section{Looking ahead: Longevity of products}

The science of ocean colour has by no means reached its apogee. There is a trend towards developing methodologies for measuring ocean colour at high temporal frequency (for example, through the use of geostationary satellites) and at high resolution in the wavelength domain (hyper-spectral remote sensing). The goals of hyper-spectral remote sensing are of course to improve the accuracy and precision of existing products and to facilitate the development of novel products. Simple band-ratio type of empirical algorithms are not designed to exploit hyperspectral capabilities. So, as we move towards hyperspectral algorithms, our choice would be to opt for multi-variate statistical methods or towards theoretical models. If one chooses purely statistical methods, it would be difficult to provide backward compatibility with simpler band-ratio algorithms in use today, unless some theoretical underpinning is 
provided to the algorithms. Without backward compatibility, the time series that is being built carefully would be interrupted. To ensure the longevity of ocean-colour products for climate change, it would be worthwhile to develop algorithms that would not become obsolete immediately the technology improved. One way to ensure longevity is to provide a theoretical basis for algorithms in use. However, any selected algorithm, theoretical or empirical, would have to meet the requirements for accuracy and precision.

Implication 20: Algorithms with a sound theoretical basis should be selected, as they are likely to be robust in the face of technological developments, and therefore to have a longer life with the proviso that the accuracy of the products also warrant the selection.

\section{Implementation in Ocean Colour Climate Change Initiative}

We now turn our attention to the outcomes, when these ideal criteria were confronted with a real-life implementation, in the case of the OC-CCI. The current status of the OC-CCI implementation is summarised in Tables 1-6. But some points are worth further emphasis. The criteria presented above emerged from a variety of considerations, but some requirements emerged multiple times, such as the need for consistency, for uncertainty estimates and for algorithms with a theoretical basis.

The requirements as listed here are not hierarchical, and in an ideal world, one would meet them all. But in reality, we found that we had to assign a hierachy to be able to make a selection. For example, in the selection of atmospheric correction algorithms, the top priority was assigned to high accuracy retrievals, then to minimising gaps in products, and finally to consis- 
tency in processing algorithms. This choice was imposed by the differences in the ocean-colour sensors (SeaWiFS, MODIS-Aqua and MERIS) used in the merged product. In the sensor-by-sensor intercomparisons carried out for the atmospheric correction processors, the same algorithms did not perform equally well for all sensors, when retrieved products were compared with match-up in situ data (Müller et al., 2015). This forced the decision that accurate products were the highest priority, and the atmospheric correction algorithm that performed best for each sensor was selected for use with data from that sensor. If two algorithms performed equally well for a particular sensor in tests related to quality of retrieval, then the algorithm that minimised gaps was given priority. Against expectation, a novel atmospheric correction algorithm (Steinmetz et al., 2011) matched the conventional algorithms in statistical comparisons, (Müller et al., 2015), but provided enhanced coverage. This atmospheric correction was implemented as a consequence, for MERIS in versions 1 and 2, and for MODIS-Aqua and MERIS in OC-CCI version 3. Implementing a novel algorithm always involves some risk, and only with time and with many applications of the products in various circumstances, will we be able to know whether the choice was the right one. That being said, at the time of writing this paper, POLYMER continues to perform well.

Similarly, in spite of a clear preference for algorithms with a strong theoretical basis, when it came to chlorophyll algorithms, more than one empirical algorithm performed better than all the theoretical-model-based algorithms in the round-robin comparisons (Brewin et al., 2015a), and so once again, algorithm performance was assigned higher priority over the requirement for 
a theoretical model. This hierarchical decision led to the choice of OC-4 algorithm in OC-CCI version 1 and in version 2, and to a combination of Ocean Colour Index or OCI (Hu et al., 2012) in version 3 in the open ocean. However, the selected algorithm for inherent optical properties (Lee et al., 2002) satisfied selection criteria for both accuracy and theoretical basis. The selection procedures implemented in OC-CCI clearly demonstrated that empirical chlorophyll algorithms are still the algorithms of choice. They also have a heritage value: since they have been use for more than two decades, the developers and users of the algorithms are very familiar with their advantages as well as their disadvantages. Therefore, if, in the near future, a theory-based algorithm outperforms all empirical algorithms, it would still be judicious to continue processing the new algorithms side by side with the OC-4 and OCI types of empirical algorithms. Comparisons between performance of algorithms would certainly help evaluate new algorithms. However, given the implicit assumptions in the band-ratio type of algorithms on how chlorophyll concentrations covary with phytoplankton community structure and with other bio-optical components in the water such as coloured dissolved organic matter, and the need for algorithms to remain robust under climate-related variability in these relationships as demonstrated by Dierssen (2010) and also illustrated in Figure 4, the need for multi-variate theretical approaches to chlorophyll retrieval remains important.

Band-shifting (Mélin \& Sclep, 2015) and bias correction (Mélin et al., 2017) of the products turned out to be important steps, since they allowed production of remote-sensing reflectances at the same wavebands for the entire merged time series. Once the bands were matched, it became possible 
to correct the data for intersensor bias, and thus improve the time series. It also followed that a common set of in-water algorithms could be implemented for all the data, without having to change wavebands (and hence algorithms) as new sensors came in and out of the time series.

In the initial years of OC-CCI the emphasis of the work was on Case-1 waters. Only in the third reprocessing (version 3), was a branching algorithm implemented on the basis of optical water classes, in a bid to improve performance in Case-2 waters. Undoubtedly, this is only the beginning, and much more work still remains to be done to improve algorithm performance in the complex optical environments encapsulated by the term Case- 2 waters. 
Table 1: Climate study requirements (general) and the OC-CCI status

\begin{tabular}{|l|l|}
\hline Requirement (general) & OC-CCI Status \\
\hline $\begin{array}{l}\text { 1. Algorithms should be robust } \\
\text { in a changing climate. }\end{array}$ & $\begin{array}{l}\text { The empirical chlorophyll-a algorithms selected for generation of } \\
\text { Chl-a products, see Brewin et al. (2015a) for details of in-water } \\
\text { algorithm comparisons contain implicit assumptions about ecoys- } \\
\text { tem structure in today's climate. Robustness would be jeopar- } \\
\text { dised if the underlying structure were altered by climate change. } \\
\text { But lack of inter-annual variations in algorithm performance (see } \\
\text { Fig. 4) is reassuring, for now. Algorithms for inherent and appar- } \\
\text { ent optical properties are based on theoretical models, and hence } \\
\text { should be more robust. But some model parameters have empiri- } \\
\text { cal bases, with the same caveats. }\end{array}$ \\
\hline $\begin{array}{l}\text { 2. Retrievals of properties of } \\
\text { the ecosystem should be inde- } \\
\text { pendent of each other. }\end{array}$ & $\begin{array}{l}\text { This criterion is met by OC-CCI products, which are all "directly" } \\
\text { retrieved from satellite-derived remote-sensing reflectance, rather } \\
\text { than through empirical correlations with each other. }\end{array}$ \\
\hline $\begin{array}{l}\text { 3. Use of empirical relationships } \\
\text { in the algorithms should be min- } \\
\text { imal. }\end{array}$ & $\begin{array}{l}\text { Chlorophyll-a algorithms used are empirical, but not the algo- } \\
\text { rithms designed for retrieval of inherent and apparent properties. }\end{array}$ \\
\hline
\end{tabular}


Table 2: Climate study requirements (Case-2) and the OC-CCI status

\begin{tabular}{|c|c|}
\hline Requirement (Case-1 and Case-2) & OC-CCI Status \\
\hline $\begin{array}{l}\text { 4. Selected Case-1 algorithms should } \\
\text { be accompanied by some estimates of } \\
\text { the increased uncertainties in products } \\
\text { when they are applied to Case- } 2 \text { waters. }\end{array}$ & $\begin{array}{l}\text { An optical classification is used in OC-CCI (Moore et al., } \\
2009 \text {; Jackson et al., 2017), which allows identification of } \\
\text { multiple classes, effectively partitioning Case-1 and Case- } \\
2 \text { into subsets according to their optical properties. Per- } \\
\text { pixel uncertainties are calculated according to membership } \\
\text { of each optical class in a pixel, and validation results for } \\
\text { each class provides uncertainties for all pixels, both Case-1 } \\
\text { and Case- } 2 \text {. }\end{array}$ \\
\hline
\end{tabular}

5. Case-1 algorithms should aim to incorporate some of the capabilities of Case-2 algorithms to discriminate between contributions from different constituents to ocean colour, albeit for conditions that might reasonably be expected in open-ocean waters.

6. Branching algorithms may be considered, for seamless blending of Case-1 and Case-2 waters.

7. If empirical algorithms are selected for climate-change studies, then a theoretical underpinning to the algorithms should be provided.

8. If a novel algorithm is selected, the new and the heritage algorithms should be reconciled through theoretical analyses. Need continued access to heritage algorithm for comparison.
This goal is not yet achieved for chlorophyll algorithm, which accounts only for the effect of chlorophyll-a concentration on ocean colour. But the optical properties in the product suite are calculated using a multi-variable approach (Lee et al., 2002), even in Case-1 waters.

Branching and blending algorithms according to optical water class have been implemented in version 3 (Jackson et al., 2017).

A number of theoretical studies have elucidated the underlying assumptions in the empirical algorithms used (e.g., Dierssen (2010) and Chapter 4 in Sathyendranath (2014)). This type of work should continue, to reach our stated goal.

A novel atmospheric correction algorithm (POLYMER, Steinmetz et al. (2011)) is used in OC-CCI for some of the sensors. Continued access to the conventional NASA SeaDAS atmospheric correction products is available through NASA. Detailed comparative analyses of the 390 types of algorithms have been beyond the scope of OCCCI, but are essential to improve understanding. 
Table 3: Climate study requirements (PFT and Phenology) and the OC-CCI status

\begin{tabular}{|l|l|}
\hline $\begin{array}{l}\text { Requirement (PFT and Phe- } \\
\text { nology) }\end{array}$ & OC-CCI Status \\
\hline $\begin{array}{l}\text { 9. Spectrally-resolved water- } \\
\text { leaving radiances and spectrally- } \\
\text { resolved phytoplankton optical } \\
\text { properties are essential. }\end{array}$ & $\begin{array}{l}\text { Products include remote-sensing reflectance at } \\
\text { all SeaWiFS wavebands (Sathyendranath et al., } \\
\text { Future improvements should include extension to all }\end{array}$ \\
\hline $\begin{array}{l}\text { 10. Check consistency in chloro- } \\
\text { phyll concentration from PFT al- } \\
\text { gorithms against that estimated } \\
\text { from blue-green ratios. }\end{array}$ & $\begin{array}{l}\text { PFT products are not included in OC-CCI product } \\
\text { this should be a goal for the future. }\end{array}$ \\
\hline $\begin{array}{l}\text { 11. The selected algorithm(s) } \\
\text { should perform routinely, glob- } \\
\text { ally, and minimise gaps. }\end{array}$ & $\begin{array}{l}\text { POLYMER atmospheric correction algorithm re- } \\
\text { duces gaps in products (Müller et al., 2015). In-water } \\
\text { algorithm round-robin included checks for number of } \\
\text { retrievals (Brewin et al., 2015a). }\end{array}$ \\
\hline
\end{tabular}


Table 4: Climate study requirements (modelling and consistency) and the OC-CCI status

\begin{tabular}{|c|c|}
\hline $\begin{array}{l}\text { Requirement (modelling, } \\
\text { consistency) }\end{array}$ & OC-CCI Status \\
\hline $\begin{array}{l}\text { 12. Different ocean-colour prod- } \\
\text { ucts have to be consistent with } \\
\text { each other (see item } 10 \text { in Table } \\
3 .\end{array}$ & $\begin{array}{l}\text { All IOPs are derived from a single bio-optical model } \\
\text { (Lee et al., 2002), to ensure consistency. But con- } \\
\text { sistency between optical properties and chlorophyll } \\
\text { concentration has not been established. }\end{array}$ \\
\hline $\begin{array}{l}\text { 13. IOPs have to be fully } \\
\text { wavelength-resolved. }\end{array}$ & $\begin{array}{l}\text { Selected algorithm provides IOPS at all SeaWiFS } \\
\text { wavelengths (Lee et al., 2002). }\end{array}$ \\
\hline $\begin{array}{l}\text { 14. To ensure consistency, } \\
\text { a common reflectance model } \\
\text { should be used for in-water re- } \\
\text { trievals and for interpolation be- } \\
\text { tween wavebands. }\end{array}$ & $\begin{array}{l}\text { The same model was used for IOP retrieval (Lee } \\
\text { et al., 2002) and band shifting (Mélin \& Sclep, 2015). }\end{array}$ \\
\hline $\begin{array}{l}\text { 15. Inter-sensor bias has to be } \\
\text { corrected, before data from mul- } \\
\text { tiple sensors can be merged. }\end{array}$ & $\begin{array}{l}\text { Bias correction has been applied at the level of } \\
\text { remote-sensing reflectance (Mélin et al., 2017). }\end{array}$ \\
\hline
\end{tabular}


Table 5: Climate study requirements (Uncertainties) and the OC-CCI status

\begin{tabular}{|l|l|}
\hline Requirement (uncertainties) & OC-CCI Status \\
\hline $\begin{array}{l}\text { 16. Uncertainties associated } \\
\text { with each of the products should } \\
\text { be minimal. }\end{array}$ & This was a selection criterion. \\
\hline $\begin{array}{l}\text { 17. The metrics selected for un- } \\
\text { certainty characterisation should } \\
\text { meet user requirements. }\end{array}$ & $\begin{array}{l}\text { Root-mean square error and bias were selected as the } \\
\text { uncertainties to report on a per-pixel basis (Jackson } \\
\text { et al., 2017), because of their wide-spread usage in } \\
\text { the field. Also consistent with the requirements of } \\
\text { the users, who requested uncertainty estimates based } \\
\text { on comparison of satellite products with in situ ob- } \\
\text { servations (Sathyendranath, 2011). }\end{array}$ \\
\hline $\begin{array}{l}\text { 18. The metrics should be imple- } \\
\text { mented on a per-pixel basis. }\end{array}$ & $\begin{array}{l}\text { Implemented using an optical classification } \\
\text { (Sathyendranath et al., 2016a,b; Jackson et al., } \\
2017) .\end{array}$ \\
\hline $\begin{array}{l}\text { 19. The shape of the retrieved } \\
\text { optical properties should match } \\
\text { the reality. }\end{array}$ & $\begin{array}{l}\text { A } \chi^{2} \text { test was implemented as part of the selection } \\
\text { criteria to test fidelity to observations (Müller et al., } \\
2015) .\end{array}$ \\
\hline
\end{tabular}

Table 6: Climate study requirements (longevity) and the OC-CCI status

\begin{tabular}{|l|l|}
\hline Requirement (longevity) & OC-CCI Status \\
\hline $\begin{array}{l}\text { 20. Algorithms with a sound the- } \\
\text { oretical basis should be selected } \\
\text { to ensure longevity. }\end{array}$ & $\begin{array}{l}\text { This is true of the optical properties in the product } \\
\text { suite. }\end{array}$ \\
\hline
\end{tabular}




\section{Conclusion}

Many aspects of the analysis above favour algorithms based on a theoretical approach, over purely empirical ones. However, the historical importance of successful empirical algorithms cannot be overlooked. Ideally, the two approaches would be reconciled, ensuring both minimal errors and improved interpretation. As the range of ocean-colour products expands, there is a need to move towards multispectral approaches in preference to simple band ratios.

Empirical relationships that tie one optical property to another are to be avoided, both in the development of forward models that establish the relationships between IOPs and ocean colour, and in the methods used to retrieve the in-water properties from ocean colour. The OC-CCI has a focus on retrieval of water-leaving radiances, chlorophyll concentration and IOPs. However, we have to be alert to the future needs for additional products from ocean colour, including detection of phytoplankton types. The preferred methods for achieving this identification, in the context of climate change, would exploit differences in the spectral characteristics of phytoplankton. The selected algorithm should be able to perform satisfactorily in a variety of oceanic and atmospheric conditions, thereby minimising gaps in data originating from choice of algorithms. A suite of qualitative and quantitative selection criteria is proposed here based on the analysis presented.

To our knowledge, this is the first time that a systematic analysis has been undertaken regarding the choices that have to be made when we set out to produce a long time series of ocean-colour products for climate research. No doubt, over the years, these ideas will be refined and improved, as our 
experience grows. Hence it is important that the rationale presented here be recognised as a first step in a long journey, and not the end.

The algorithm selections, in practice, relies heavily on in situ data for their assessments. The importance of maintaining and building on the in situ datasets (as well as improving the collection methods) for monitoring the performance of the satellite sensors, and for monitoring the performance of the products produced by the algorithms has to be underscored in this context. Only with good sea truth data can we have confidence in the climate products generated using the algorithms.

Without doubt, many of the issues discussed here with respect to consistency will become easier to deal with, once operational ocean-colour missions, notably the Sentinel-3 series, have been available for several decades. The beginning of the Sentinel-3 era is here, with the launch of the first of the Sentinel-3 missions in 2016. It will prove to be a landmark in the development of long time series of ocean-colour products for climate research.

\section{Acknowledgements}

This work is a contribution to the Ocean Colour component of the Climate Change Initiative of the European Space Agency. Additional support from the National Centre for Earth Observation of the Natural Environment Research Council of the UK is also acknowledged.

\section{References}

Alvain, S., Moulin, C., Dandonneau, Y., \& et al. (2005). Remote sensing of phytoplankton groups in case 1 waters from global seawifs imagery. Deep- 
Sea Research, I, 52, 1989-2004.

Antoine, D., André, J.-M., \& Morel, A. (1996). Oceanic primary production 2. estimation at global scale from satellite (coastal zone color scanner) chlorophyll. Global Biogeochemical Cycles, 10, 57-69.

Bouman, H., Platt, T., Sathyendranath, S., Irwin, B., Wernand, M., \& Kraay, G. (2000). Bio-optical properties of the subtropical north atlantic. ii. relevance to models of primary production. Mar. Ecol. Prog. Ser., 200, 19-34.

Bracher, A., Vountas, M., Dinter, T., Burrows, J., Röttgers, R., \& Peeken, I. (2009). Quantitative observation of cyanobacteria and diatoms from space using phytodoas on sciamachy data. Biogeosciences, 6, 751-764.

Brewin, R. (2011). Detecting Phytoplankton Size Class Using Satellite Earth Observation. Ph.D. thesis University of Plymouth.

Brewin, R., Hirata, T., Hardman-Mountford, N., Lavender, S., Sathyendranath, S., \& Barlow, R. (2012). The influence of the indian ocean dipole on interannual variations in phytoplankton size structure as revealed by earth observations. Deep Sea Res., 7780, 117127.

Brewin, R., Sathyendranath, S., Muüller, D., Brockmann, C., Deschamps, P.-Y., Devred, E., Doerffer, R., Fomferra, N., Franz, B., Grant, M., Groom, S., Horseman, A., Hu, C., Krasemann, H., Lee, Z., Maritorena, S., Mélin, F., Peters, M., Platt, T., Regner, P., Smyth, T., Steinmetz, F., Swinton, J., Werdell, J., \& White, I., GN (2015a). The ocean colour climate change initiative: Iii. a round-robin comparison on in-water bio-optical algorithms. Remote Sensing of Environment, 162, 271-294. 
Brewin, R. J., Sathyendranath, S., Jackson, T., Barlow, R., Brotas, V., Airs, R., \& Lamont, T. (2015b). Influence of light in the mixed layer on the parameters of a three-component model of phytoplankton size structure. Remote Sensing of Environment, 168, 437450.

Brewin, R. J. W., Sathyendranath, S., Takafumi, H., Lavender, S. J., Barciela, R. M., \& Hardman-Mountford, N. J. (2010). A three-component model of phytoplankton size class for the atlantic ocean. Ecological Modelling, 221, 14721483.

Bricaud, A., Babin, M., Claustre, H., Ras, J., \& Tiéche, F. (2010). Light absorption properties and absorption budget of southeast pacific waters. Journal of Geophysical Research, 115, C08009.

Chisholm, S. (1992). Phytoplankton size. In P. Falkowski, \& A. Woodhead (Eds.), Primary Productivity and Biogeochemical Cycles in the Sea (p. 213237). Springer.

Ciotti, A. M., \& Bricaud, A. (2006). Retrievals of a size parameter for phytoplankton and spectral light absorption by coloured detrital matter from water-leaving radiances at seawifs channels in a continental shelf off brazil. Limnology and Oceanography: Methods, 4, 237253.

Devred, E., Sathyendranath, S., \& Platt, T. (2009). Decadal changes in ecological provinces of the northwest atlantic ocean revealed by satellite observations. Geophys. Res. Letters, .

Devred, E., Sathyendranath, S., Stuart, V., \& Platt, T. (2011). A three com- 
ponent classification of phytoplankton absorption spectra: Applications to ocean-colour data. Remote Sensing of Environment, 115.

Di Lorenzo, E., \& Ohman, M. D. (2013). A double-integration hypothesis to explain ocean ecosystem response to climate forcing. Proceedings of the National Academy of Sciences, 110, 2496-2499.

Dierssen, H. (2010). Perspectives on empirical approaches for ocean color remote sensing of chlorophyll in a changing climate. Proceedings of the National Academy of Sciences, 107, 17073-17078.

Franz, B., \& Werdell, P. J. (2010). A generalized framework for modeling of inherent optical properties in ocean remote sensing applications. In Ocean Optics XX, 27th Sept.1st Oct. 2010. Anchorage, Alaska.

Friedrichs, M. et al. (2009). Assessing the uncertainties of model estimates of primary productivity in the tropical pacific ocean. Journal of Marine Systems, 76, 113-133.

Garver, S. A., \& Siegel, D. A. (1997). Inherent optical property inversion of ocean color spectra and its biogeochemical interpretation: 1. time series from the sargasso sea. Journal of Geophysical Research, 102.

GCOS (2004). Global Climate Observing System. Implementation plan for the global observing system for climate in support of the UNFCCC. Technical Report GCOS.

Gordon, H. R., Brown, O. B., Evans, R. H., Brown, J., Smith, R. C., Baker, K. S., \& Clark, S. K. (1988). A semianalytic radiance model of ocean color. Journal of Geophysical Research, 93, 10,90910,924. 
Hu, C., Lee, Z., \& Franz, B. (2012)). Chlorophyll a algorithms for oligotrophic oceans: A novel approach based on three-band reflectance difference. $J$. Geophys. Res., 117, C01011.

Huot, Y., Morel, A., Twardowski, M. S., Stramski, D., \& Reynolds, R. A. (2008). Particle optical backscattering along a chlorophyll gradient in the upper layer of the eastern south pacific ocean. Biogeosciences, 5, 495507.

Jackson, T., Sathyendranath, S., \& Mélin, F. (2017). An improved optical classification scheme applied to ocean colour. Remote Sensing of Environment, under review.

Koeller, P., Fuentes-Yaco, C., Platt, T., Sathyendranath, S., Richards, A., Ouellet, P., Orr, D., Skúladóttir, U., Wieland, K., Savard, L., \& Aschan, M. (2009). Basin-scale coherence in phenology of shrimps and phytoplankton in the north atlantic ocean. Science, 324.

Kostadinov, T. S., Siegel, D. A., \& Maritorena, S. (2009). Retrieval of the particle size distribution from satellite ocean color observations. Journal of Geophysical Research, 114, C09015.

Kostadinov, T. S., Siegel, D. A., \& Maritorena, S. (2010). Global variability of phytoplankton functional types from space: assessment via the particle size distribution. Biogeosciences, 7, 32393257.

Le Quéré, C., Harrison, S., Prentice, I., Buitenhuis, E., Aumont, O., Bopp, L., Claustre, H., da Cunha, L., Geider, R., Giraud, X., Klaas, C., Kohfeld, K., Legendre, L., Manizza, M., Platt, T., Rivkin, R., Sathyendranath, 
S., Uitz, J., Watson, A., \& Wolf-Gladrow, D. (2005). Ecosystem dynamics based on plankton functional types for global ocean biogeochemistry models. Global Change Biology, 11, 2016-2040.

Lee, Z., Carder, K. L., \& Arnone, R. A. (2002). Deriving inherent optical properties from water color: A multiband quasi-analytical algorithm for optically deep waters. Applied Optics, 41, 5755-5772.

Lee, Z.-P., \& Hu, C. (2006). Global distribution of case-1 waters: An analysis from seawifs measurements. Remote Sens. Environ., 101, 270276.

Li, W., McLaughlin, F., Lovejoy, C., \& Carmack, E. (2009). Smallest algae thrive as the arctic ocean freshens. Science, 326, 539-539.

Loisel, H., Lubac, B., Dessailly, D., Duforet-Gaurier, L., \& Ventrepotte, V. (2010). Effect of inherent optical properties variability on the chlorophyll retrieval from ocean color remote sensing: An in situ approach. Optics Express, 8 .

Longhurst, A., Sathyendranath, S., Platt, T., \& Caverhill, C. (1995). An estimate of global primary production in the ocean from satellite radiometer data. Jourlan of Plankton Research, 17, 1245-1271.

Lurin, B., Rasool, S., Cramer, W., \& Moore, B. (1994). Global terrestrial net primary production. Global Change Newsletter (IGBP), 19, 6-8.

Maritorena, S., Siegel, D. A., \& Peterson, A. (2002). Optimization of a semianalytical ocean color model for global-scale applications. Applied Optics, 41, 27052714. 
Martinez, E., Antoine, D., D’Ortenzio, F., \& Gentili, B. (2009). Climatedriven basin-scale decadal oscillations of oceanic phytoplankton. Science, 326, 1253-1256.

Mélin, F. (2016). Impact of inter-mission differences and drifts on chlorophylla trend estimates. International Journal of Remote Sensing, 37.

Mélin, F., \& Sclep, G. (2015). Band shifting for ocean color multi-spectral reflectance data. Optics Express, 23, 2262-2279.

Mélin, F., Ventrepotte, V., Chuprin, A., Grant, M., Jackson, T., , \& Sathyendranath, S. (2017). Assessing the fitness-for-purpose of satellite multimission ocean color climate data records: A protocol applied to oc-cci chlorophyll-a data. Remote Sensing of Environment, this special issue, in revision.

Moore, T., Campbell, J., \& Dowell, M. (2009). A class-based approach to characterizing and mapping the uncertainty of the modis ocean chlorophyll product. Remote Sensing of Environment, 113, 24242430.

Morel, A. (2009). Are the empirical relationships describing the bio-optical properties of case 1 waters consistent and internally compatible? Journal of Geophysical Research, 114, C01016.

Morel, A., \& Antoine, D. (2011). MERIS algorithm theoretical basis documents (ATBD 2.9) - Pigment index retrieval in Case 1 waters (PO-TNMEL-GS-0005), Issue 4, July 2011. MERIS ESL, ACRI-ST. Technical Report Laboratoire d'Océanographie de Villefranche (LOV). 
Morel, A., Gentili, B., Chami, M., \& Ras, J. (2006). Bio-optical properties of high chlorophyll case 1 waters and of yellow-substance-dominated case 2 waters. Deep-Sea Research I, 53, 14391459.

Morel, A., \& Prieur, L. (1977). Analysis of variations in ocean color. Limnology and Oceanography, (pp. 709-722).

Müller, D., Krasemann, H., Brewin, R., Brockmann, C., Deschamps, P.Y., Doerffer, R., Fomferra, N., Franz, B., Grant, M., Groom, S., Mélin, F., Platt, T., Regner, P., Sathyendranath, S., Steinmetz, F., \& Swinton, J. (2015). The ocean colour climate change initiative: I. a methodology for assessing atmospheric correction processors based on in-situ measurements. Remote Sensing of Environment, 162, 242-256.

Nair, A., Sathyendranath, S., Platt, T., Morales, J., Stuart, V., Forget, M.H., Devred, E., \& Bouman, H. (2008). Remote sensing of phytoplankton functional types. Remote Sensing of Environment, 112, 33663375.

O'Reilly, J., Maritorena, S., Mitchell, B., Siegel, D., Carder, K., Garver, S., Kahru, M., \& McClain, C. (1998). Ocean color chlorophyll algorithms for seawifs. Journal of Geophysical Research, 103, 24937-24953.

O'Reilly, J. E., Maritorena, S., Siegel, D., \& O'Brien, M. C. (2000). Ocean color chlorophyll a algorithms for seawifs, oc2, and oc4: Technical report. In D. Toole, B. G. Mitchell, M. Kahru, F. P. Chavez, P. Strutton, G. Cota, S. B. Hooker, C. R. McClain, K. L. Carder, F. Muller-Karger, L. Harding, A. Magnuson, D. Phinney, G. F. Moore, J. Aiken, K. R. Arrigo, R. Letelier, M. Culver, S. B. Hooker, \& E. R. Firestone (Eds.), SeaWiFS postlaunch 
calibration and validation analyses, Part 3 (p. 923). Greenbelt, Maryland: NASA, Goddard Space Flight Center volume 11 of SeaWiFS Postlaunch Technical Report Series.

Platt, T., Broomhead, D., Sathyendranath, S., Edwards, A., \& Murphy, E. (2003a). Phytoplankton biomass and residual nitrate in the pelagic ecosystem. Proc. R. Soc. Lond. A, 459, 1063-1073.

Platt, T., Fuentes-Yaco, C., \& Frank, K. (2003a). Spring algal bloom and larval fish survival. Nature, 423, 398-399.

Platt, T., \& Jassby, A. (1976). The relationship between photosynthesis and light for natural assemblages of coastal marine phytoplankton. Journal of Phycology, 12, 421-430.

Platt, T., Sathyendranath, S., Edwards, A., Broomhead, D., \& Ulloa, O. (2003b). Nitrate supply and demand in the mixed layer of the ocean. Mar. Ecol. Prog. Ser., 254, 3-9.

Pope, R., \& Fry, E. (1997). Absorption spectrum (380-700 nm) of pure water. ii. integrating cavity measurements. Applied Optics, 36, 87108723.

Prieur, L., \& Sathyendranath, S. (1981). An optical classification of coastal and oceanic waters based on the specific spectral absorption curves of phytoplankton pigments, dissolved organic matter, and other particulate materials. Limnol. Oceanogr., 26, 671-689.

Racault, M.-F., Sathyendranath, S., Menon, N., \& Platt, T. (2016). Phenological responses to enso in the global oceans. Surveys in Geophysics, 38 , 277-293. 
Sathyendranath, S. (Ed.) (2000). Remote sensing of ocean colour in coastal, and other optically-complex, waters. Reports of the Ocean Colour Coordinating Group, No. 3. Dartmouth, Canada: IOCCG.

Sathyendranath, S. (2011). User requirements document. Ref: D1.1 Issue 1.10. Technical Report ESA/ESRIN.

Sathyendranath, S. (Ed.) (2014). Phytoplankton Functional Types from Space. Reports of the International Ocean-Colour Coordinating Group, No. 15. Dartmouth, Canada: IOCCG.

Sathyendranath, S., Gouveia, A., Shetye, S., Ravindran, P., \& Platt, T. (1991). Biological control of surface temperature in the arabian sea. $N a$ ture, $349,54-56$.

Sathyendranath, S., Groom, S., Grant, M., Brewin, R., Thompson, A., Chuprin, A., Horseman, A., Jackson, T., Martinez Vicente, V., Platt, T., Brockmann, C., Z'uhlke, M., Doerffer, R., Valente, A., Brotas, V., Krasemann, H., M'uller, D., Dowell, M., Mélin, F., Swinton, J., Farman, A., Lavender, S., Moore, T., Regner, P., Roy, S., Steinmetz, F., Mazeran, C., Brando, V., Taberner, M., Antoine, D., Arnone, R., Balch, W., Barker, K., Barlow, R., Bélanger, S., Berthon, J., Beşiktepe, c., Canuti, E., Chavez, F., Claustre, H., Crout, R., Frouin, R., García-Soto, C., Gibb, S., Gould, R., Hooker, S., Kahru, M., Klein, H., Kratzer, S., Loisel, H., McKee, D., Mitchell, B., Moisan, T., Feldman, G., Franz, B., Muller-Karger, F., O’Dowd, L., Ondrusek, M., Poulton, A., Repecaud, M., Smyth, T., Sosik, H., Twardowski, M., Voss, K., Werdell, J., Wernand, M., \& Zibordi, G. (2016a). ESA Ocean Colour Climate Change Initiative (Ocean- 
Colour-cci): Version 1.0 Data. http://dx.doi.org/10.5285/E32FEB535DB1-44BC-8A09-A6275BA99407. Technical Report Centre for Environmental Data Analysis.

Sathyendranath, S., Groom, S., Grant, M., Brewin, R. J. W., Thompson, A., Chuprin, A., Horseman, A., Jackson, T., Martinez Vicente, V., Platt, T., Brockmann, C., Zühlke, M., Doerffer, R., Valente, A., Brotas, V., Krasemann, H., Müller, D., Dowell, M., Mlin, F., Swinton, J., Farman, A., Lavender, S., Moore, T. S., Regner, P., Roy, S., Steinmetz, F., Mazeran, C., Brando, V. E., Taberner, M., Antoine, D., Arnone, R., Balch, W. M., Barker, K., Barlow, R., Bélanger, S., Berthon, J., Beşiktepe, c., Canuti, E., Chavez, F., Claustre, H., Crout, R., Frouin, R., GarcíaSoto, C., Gibb, S. W., Gould, R., Hooker, S., Kahru, M., Klein, H., Kratzer, S., Loisel, H., McKee, D., Mitchell, B. G., Moisan, T., Feldman, G., Franz, B., Muller-Karger, F., O’Dowd, L., Ondrusek, M., Poulton, A. J., Repecaud, M., Smyth, T., Sosik, H. M., Twardowski, M., Voss, K., Werdell, J., Wernand, M., \& Zibordi, G. (2016b). ESA Ocean Colour Climate Change Initiative (Ocean-Colour-CCI): Version 2.0 Data, http://dx.doi.org/10.5285/b0d6b9c5-14ba-499f-87c9-66416cd9a1dc. Technical Report.

Sathyendranath, S., \& Morel, A. (1983). Light emerging from the sea interpretation and uses in remote sensing. In A. P. Cracknell (Ed.), Remote Sensing Applications in Marine Science and Technology (pp. 323-357). Dordrecht: D. Reidel Publishing Company.

Sathyendranath, S., \& Platt, T. (2007). Spectral effects in bio-optical control 
on the ocean system. Oceanologia, 49, 5-39.

Sathyendranath, S., Prieur, L., \& Morel, A. (1989). A three-component model of ocean colour and its application to remote sensing of phytoplankton pigments in coastal waters. Int. J. Remote Sens., 10, 1373-1394.

Sathyendranath, S., Watts, L., Devred, E., Platt, T., Caverhill, C., \& Maass, H. (2004). Discrimination of diatoms from other phytoplankton using ocean-colour data. Mar Ecol Prog Ser, 272, 59-68.

Siegel, D., Maritorena, S., Nelson, N., \& Behrenfeld, M. (2005). Independence and interdependencies of global ocean color properties: re-assessing the bio-optical assumption. Journal of Geophysical Research, 110, C07011.

Siegel, D. A., Maritorena, S., Nelson, N. B., Hansell, D. A., \& LorenziKayser, M. (). Global distribution and dynamics of colored dissolved and detrital organic materials. Journal of Geophysical Research, $10 \%$.

Steinmetz, F., Deschamps, P.-Y., \& Ramon, D. (2011). Atmospheric correction in presence of sun glint: application to meris. Opt. Express, 19, 9783-9800.

Szeto, M., Werdell, P., Moore, T., \& Campbell, J. (2011). Are the world's oceans optically different? Journal of Geophysical Research, 116, C00H04.

Uitz, J., Claustre, H., Morel, A., \& Hooker, S. B. (2006). Vertical distribution of phytoplankton communities in open ocean: An assessment based on surface chlorophyll. Journal of Geophysical Research, 111. 